NASA Technical Memorandum 107210

\title{
Atomic Oxygen Durability of Second Surface Silver Microsheet Glass Concentrators
}

Kim K. de Groh and Donald A. Jaworske

Lewis Research Center

Cleveland, Ohio

Daniela C. Smith

Cleveland State University

Cleveland, Ohio

Thaddeus S. Mroz

Lewis Research Center

Cleveland, Ohio

Prepared for the

Third International Conference on Protection of Materials and Structures

from the Low Earth Orbit Space Environment

cosponsored by the Canadian Space Agency and the

Institute for Space and Terrestrial Studies

Toronto, Canada, April 25-26, 1996

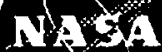

National Aeronautics and

Space Administration 


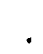




\title{
ATOMIC OXYGEN DURABILITY OF SECOND SURFACE SILVER MICROSHEET GLASS CONCENTRATORS
}

\author{
Kim K. de Groh \\ Donald A. Jaworske \\ National Aeronautics and Space Administration \\ Lewis Research Center \\ Cleveland, Ohio 44135 \\ Daniela C. Smith \\ Cleveland State University \\ Cleveland, Ohio 44115 \\ Thaddeus S. Mroz \\ Distinguished Research Associate \\ National Aeronautics and Space Administration \\ Lewis Research Center \\ Cleveland, Ohio 44135
}

\begin{abstract}
Second surface silver microsheet glass concentrators are being developed for potential use in future solar dynamic space power systems. Traditional concentrators are aluminum honeycomb sandwich composites with either aluminum or graphite epoxy face sheets, where a reflective aluminum layer is deposited onto an organic leveling layer on the face sheet. To protect the underlying layers, a $\mathrm{SiO}_{2}$ layer is applied on top of the aluminum reflective layer. These concentrators may be vulnerable to atomic oxygen degradation due to possible atomic oxygen attack of the organic layers at defect sites in the protective and reflective coatings. A second surface microsheet glass concentrator would be inherently more atomic oxygen durable than these first surface concentrators. In addition, a second surface microsheet glass concentrator design provides a smooth optical surface and allows for silver to be used as a reflective layer, which would improve the reflectivity of the concentrator and the performance of the system. A potential threat to the performance of second surface microsheet glass concentrators is atomic oxygen attack of the underlying silver at seams and edges or at micrometeoroid and debris (MMD) impacts sites. Second surface silver microsheet glass concentrator samples were fabricated and tested for atomic oxygen durability. The samples were iteratively exposed to an atomic oxygen environment in a plasma asher. Samples were evaluated for potential degradation at fabrication seams, simulated MMD impact sites, and edges. Optical microscopy was used to evaluate atomic oxygen degradation. Reflectance was obtained for an impacted sample prior to and after atomic oxygen exposure. After an initial atomic oxygen exposure to an effective fluence of $\approx 1 \times 10^{21}$ atoms $/ \mathrm{cm}^{2}$, oxidation of the silver at defect sites and edges was observed. Exposure to an additional $\approx 1 \times 10^{21}$ atoms $/ \mathrm{cm}^{2}$ caused no observed increase in oxidation. Oxidation at an impact site caused negligible changes in reflectance. In
\end{abstract}


all cases oxidation was found to be confined to the vicinity of the seams, impact sites, edges or defect sites. Asher to in-space atomic oxygen correlation issues will be addressed.

\section{INTRODUCTION}

Solar dynamic power systems require solar concentrators that are efficient, durable, and light weight. To be efficient, the concentrator must have a high reflectivity and a high surface accuracy. Reflective coatings commonly considered for solar dynamic concentrators include silver and aluminum. 1,2 High surface accuracy is often achieved by applying an organic leveling or smoothing coating to an aluminum or graphite epoxy face sheet. ${ }^{3,4}$ To be durable to the low Earth orbital atomic oxygen environment, a thin protective coating of silicon dioxide (typically $\approx 1000 \AA$ ) is often used to protect the underlying layers from oxidation. Therefore, a typical solar concentrator has the following composition: protective layer $(\approx 1000 \AA) /$ reflective layer/leveling layer/substrate layers. Even with a protective coating, these concentrators may be vulnerable to atomic oxygen degradation due to possible atomic oxygen attack of the organic layers at defect sites in the protective and reflective coatings. For example, $\mathrm{SiO}_{\mathrm{x}}$ (where $\mathrm{x}$ is between 1.8 and 2.0) protective coatings on Kapton for solar array blankets for Space Station were found to have average defect densities of $\approx 2600 / \mathrm{cm}^{2} .5$ These defects (pinhole type) are the result of surface irregularities and dust or debris on the unprotected material that did not allow uniform coating during the deposition process.

Atomic oxygen undercutting erosion at protective coating defect sites has been well documented in ground laboratory testing. ${ }^{6,7}$ The Long Duration Exposure Facility (LDEF) which was in low Earth orbit (LEO) for 5.8 years provided evidence of in-space undercutting erosion. Aluminized Kapton multilayer insulation samples and protected graphite epoxy samples from the leading edge of LDEF were found to be undercut even though the leading edge received near normal incident ram atomic oxygen impingement. ${ }^{8,9}$ Atomic oxygen undercutting with normal incidence ram attack can occur because there are atomic oxygen velocity components which are transverse to the ram direction. These transverse components are due to thermal velocity, orbital inclination and scattering contributions. ${ }^{8}$ Because a solar concentrator will be sun tracking, it will be exposed to sweeping ram atomic oxygen where the ram direction continuously changes with respect to the concentrator surface. Atomic oxygen undercutting will be shallower but much wider for sweeping ram exposures than fixed ram exposures. Therefore, systems such as solar concentrators, which receive sweeping ram exposure are more susceptible to undercutting erosion.

Silver has a greater integrated solar reflectance than aluminum, by several percentage points. Figure 1 shows the spectral difference and the corresponding integrated solar reflectance values for both silver and aluminum microsheet glass first surface mirrors (the reflective layer is on the front side of the microsheet glass). This distinct advantage of silver is offset in LEO applications by its high rate of oxidation by atomic oxygen. Aluminum, on the other hand, develops a very thin, passive oxide layer which makes it atomic oxygen durable. Therefore, aluminum, which is a poorer optical performer than silver, is generally a more durable reflective choice for conventional solar concentrators. 
One concept being considered to enable the use of silver as a reflective layer in LEO applications is a second surface silver microsheet glass concentrator. In this concentrator, the silver is deposited onto the back side of a suitably curved piece of microsheet glass $(\approx 0.2 \mathrm{~mm}$ thick). The microsheet glass not only serves as a smooth and accurate surface, but also serves as a substantial barrier to atomic oxygen attack. Microsheet glass concentrators have been investigated at NASA Lewis Research Center since $1988 .{ }^{10}$ One of the disadvantages of microsheet glass concentrators is limitations of the commercially available size. Currently, microsheet glass is available in widths of $0.356 \mathrm{~m}$ and lengths of $9.14 \mathrm{~m}$. Solar concentrators, such as the one in NASA Lewis Research Center's $2 \mathrm{~kW}$ Solar Dynamic Ground Test Demonstration system, have triangular shaped facets with $\approx 0.8 \mathrm{~m}$ sides. ${ }^{2}$ Therefore, facets made from microsheet glass would need to have several seams. These seams may be locations for potential environmental degradation.

Although microsheet glass concentrators are inherently durable to atomic oxygen erosion, micrometeoroid and debris particles present in the LEO environment pose a potential threat to concentrator durability. Micrometeoroid and debris particles impact spacecraft with high velocity and energy. Even though a typical collision induces highly localized damage that generally is not detrimental to systems ${ }^{11}$, these impact sites are likely to provide pathways for atomic oxygen attack of the underlying silver and organic layers. For example, extensive oxidation was observed at impact sites in second surface silverized Teflon thermal control blankets retrieved from LDEF. ${ }^{11}$

The purpose of this work was to evaluate the atomic oxygen durability of second surface silver microsheet glass concentrators, with special emphasis placed on the durability of seams, simulated MMD impact sites and edges.

\section{MATERIALS AND EXPERIMENTAL PROCEDURE}

\section{Materials \& Fabrication Procedures}

A total of three microsheet glass concentrator samples were prepared for atomic oxygen exposure. Figure 2 summarizes the layered construction of the microsheet glass samples used for testing. A $0.216 \mathrm{~mm}$ thick borosilicate microsheet glass is on the top, followed by $5000 \AA$ of silver, followed by a thin film $(0.038 \mathrm{~mm})$ of Dow Corning XZ-7125 silicone adhesive, all on top of a substrate material. Although several substrate materials have been considered so far (aluminum, magnesium and graphite epoxy for example), two substrates were chosen for these atomic oxygen exposure tests, $0.216 \mathrm{~mm}$ thick microsheet glass and $2.286 \mathrm{~mm}$ thick graphite epoxy. Microsheet glass was used as a substrate (as opposed to aluminum or magnesium) because it is atomic oxygen durable and allows the adhesive layer to be observed during testing. The Dow Corning thin film adhesive was used because it is a space qualified material. It should be noted that there is a potential for some contamination due to environmental interaction with the silicone adhesive contained in the DC XZ-7125, but the risk is greatly decreased because only the silicone at the edges could be exposed to some atomic oxygen, and should not be directly exposed to UV radiation in space. 
The fabrication process chosen to make the microsheet glass samples was as follows. First, the substrates and microsheet glass covers were formed into rectangular flat panels (3.5 $\times 5.0 \mathrm{~cm}$ and $5.0 \mathrm{~cm} \times 5.0 \mathrm{~cm}$ ). Chemical cleaning of the substrates and the glass covers followed, using a chemical cleaning technique developed at the Lewis Research Center. The silver layer was applied to the second surface (back side) of the microsheet glass cover via vapor deposition. Next, the adhesive was bonded to the substrate. Finally, a protective film on the non-adhered side of the thin film adhesive was removed and the silver-coated side of the microsheet glass cover was slowly brought into contact with the adhesive.

As previously stated, three samples were fabricated and tested. The first sample, SS1, was prepared with a microsheet glass substrate and had a seam down the center of the microsheet glass cover. The primary purpose for testing this sample was to evaluate the degradation of concentrators in the vicinity of seams. The second sample, MD1, also had a microsheet glass substrate, but this sample was purposely prepared with two simulated micrometeoroid and debris impact sites. The MMD impacts were introduced manually by breaking the microsheet glass with a sharp implement. The third sample, GS1, was fabricated with a graphite epoxy substrate. This sample, which did not have seams or induced impact sites, was used to evaluate edge effects and to compare edge oxidation with the microsheet glass substrate samples. Graphite epoxy will be eroded by atomic oxygen so it has a greater potential for degradation at its edges than concentrators with atomic oxygen durable substrates. Because atomic oxygen arrival is isotropic in the atomic oxygen facility used, a microsheet glass layer was adhesively applied to the back of the graphite epoxy substrate to protect it from atomic oxygen attack. Graphite epoxy as a substrate has the advantage of being light weight, structurally strong and can be formed to any shape. Pre-exposure photographs of the three samples are shown in Figure 3.

\section{Atomic Oxygen Exposure}

The samples were iteratively exposed to an atomic oxygen environment in a $13.56 \mathrm{MHz}$, RF discharge plasma asher operated on air. The SPI Supplies Plasma Prep 2 facility operates under a partial vacuum of approximately $100 \mathrm{mtorr}$ and generates a plasma that contains oxygen atoms, ions, and molecules in various states. ${ }^{7,12}$ The effective atomic oxygen fluence that the samples received was calculated based on the mass loss/area of unprotected Kapton witness coupons which have a known erosion yield of $3 \times 10^{-24} \mathrm{~cm}^{3} /$ atom in LEO. ${ }^{12}$ Because of the size of the samples, they were placed on two shelves in the asher. Each shelf had its own fluence witness coupon. Samples GS1 and MD1 were exposed to an initial atomic oxygen effective fluence of $1.1 \times 10^{21}$ atoms $/ \mathrm{cm}^{2}$, and sample SS1 was exposed to an initial effective fluence of $1.3 \times 10^{21}$ atoms $/ \mathrm{cm}^{2}$. The samples were characterized and then exposed to an additional fluence of $0.9 \times 10^{21}$ atoms $/ \mathrm{cm}^{2}$ for samples GS1 and MD1, and $0.7 \times 10^{21}$ atoms $/ \mathrm{cm}^{2}$ for sample SS1, for a total atomic oxygen effective fluence of $2.0 \times 10^{21}$ atoms $/ \mathrm{cm}^{2}$ for all.

Although the purpose of this study was to evaluate the atomic oxygen durability of these samples, it should be noted that there is a strong vacuum ultraviolet (VUV) radiation line at 130 $\mathrm{nm}$ in the plasma environment, so that the samples were also exposed to VUV radiation in the asher. ${ }^{12}$ 


\section{Optical Characterization}

Black and white photographs of all pristine and atomic oxygen exposed samples were taken with a Polaroid Land camera. Black and white micrographs (12-101 X) of defect sites, seams and edges were obtained using an Olympus SZH Stereo Microscope. Optical microscopy evaluation was used as the primary technique for characterizing oxide growth.

Reflectance measurements were obtained over a wavelength range of $250-2500 \mathrm{~nm}$ using a Perkin Elmer $\lambda-9$ Spectrophotometer operated with a $150 \mathrm{~mm}$ integrating sphere. Specular reflectance was measured at an $8^{\circ}$ off-normal angle. Integrated solar reflectance values were calculated by convoluting the spectral data into the air mass zero solar spectrum over the same wavelength range. Sample MD1, which had the simulated MMD impact sites, was the only atomic oxygen exposed sample characterized for optical properties. The measurements were taken with an impact site positioned in the center of the reflectance port.

\section{RESULTS AND DISCUSSION}

\section{Characterization Prior to Atomic Oxygen Exposure}

Due to time constraints, these samples were made relatively quickly, which resulted in some imperfections in the as-fabricated samples. For example, there were some hazy areas present on the samples. One such area is visible on the left side of sample SS1 (see Figure 3a). There are also hazy areas along the left edge of sample MD1, and along the bottom edge of sample GS1, as can be seen in Figures $3 b$ and 3c, respectively. These hazy areas appear to be due to chemical residues from the cleaning process, which have reacted with the silver. Also, there is a circular crack site on sample SS1 extending from the left side of the upper edge. This crack, which was induced accidentally, is in addition to the seam, which appears as a straight line down the center of the sample. Aside from the hazy patches, these as-fabricated samples had a very high specular appearance. In viewing the backsides of the samples, there were some air pockets present in the adhesive. These air bubbles were present around some of the defect areas such as the impact sites and the curved crack in SS1. Air entrapment can be avoided with special care in applying the film adhesive.

The integrated solar values for total, diffuse and specular reflectances of sample MD1 were $0.936,0.049$ and 0.887 , respectively. The relatively large diffuse reflectance $(4.9 \%)$ for this mirrored sample is due to the purposely centered impact site. Optical properties were obtained for a similarly coated second surface silver microsheet glass mirror not used for atomic oxygen durability evaluation. The integrated solar values for this non-defected mirror were $0.938,0.016$ and 0.922 , for total, diffuse and specular reflectance, respectively. It is interesting to note, that for the second surface mirrors the microsheet glass absorbs most of the light which is reflected from the first surface mirror below $\approx 325 \mathrm{~nm}$ (see Figure 1a). 


\section{Atomic Oxygen Exposure Results}

After an initial atomic oxygen exposure to an effective fluence of $\approx 1.2 \times 10^{21}$ atoms $/ \mathrm{cm}^{2}$, oxidation was clearly visible on all samples (see Figure 4). Figure 4a shows sample SS1 after initial atomic oxygen exposure (compare this photo with the pristine sample in Figure $3 a$ ). Oxidation is apparent as the bright white regions on some edge areas and at the curved crack site of the sample. Oxidation occurred along only a small section of the seam. The oxidation which occurred on sample SS1 appears to have developed at observable fabrication imperfections, such as the curved crack. There are visible imperfections in the pristine sample along the top and bottom edges where oxidation took place (see Figure 3a). There also seems to be a correlation between oxidation and the presence of air pockets in the adhesive. For example, there are air pockets in the adhesive around the curved crack, along the area of the seam which oxidized and at the lower right corner of the sample which oxidized. There are some areas where air pockets are present which did not oxidize because there are no corresponding crack sites in the microsheet glass (seams or edges) to provide a pathway for atomic oxygen exposure. Finally, there appears to be adhesion failure, between the silver and adhesive, associated with the relatively large curved oxidized regions extending into the sample from the lower left edge of sample SS1. It is not know if the adhesion failure occurred prior to, or during exposure. It should be noted that photographic exposure variations for the photographs in Figures 3-5 caused slight under-exposure of the atomic oxygen tested samples compared to the pristine samples. This is why less features are visible on the atomic oxygen exposed samples.

Oxidation was present along some, but not all radial cracks around the two impact sites in sample MD1 (see Figure 4b). Some of these cracks extend across the entire sample, but the oxidation is present only near the impact site. Oxidation was present along most edges of the graphite epoxy based sample GS1. Compare the top and right edges in Figure 4c with those in Figure $3 \mathrm{c}$. It should be noted, that the silverized microsheet glass cover overhangs this sample on most edges, by about $1 \mathrm{~mm}$ on the top side, exposing the silver directly to the atomic oxygen plasma. However, the extent of oxide growth is $\approx 1.2 \mathrm{~mm}$ into the graphite epoxy in this area (a total of $2.2 \mathrm{~mm}$ oxide growth). There was no observable oxidation at an edge where the graphite epoxy lines up with the cover glass. Oxidation of the overhung edge may be affected by scattering contributions, or it is possible that the adhesive was not completely bonded to the cover sheet at these edges. There appears to be a very small gap between the microsheet glass and the graphite epoxy at the extreme edges of the sample as seen from the backside of the sample. If this gap was also present between the silverized microsheet glass and graphite epoxy it may explain why the silver has oxidized along these edges. It is not clear if these gaps were present prior to exposure, or occurred due to atomic oxygen exposure. The silver at the edges of the graphite epoxy sample did appear to be somewhat more susceptible to oxidation than the silver at the edges of the microsheet glass samples, but the edges of the microsheet glass substrate samples may have been bonded better.

Exposure to an additional effective fluence of $0.7-0.9 \times 10^{21}$ atoms $/ \mathrm{cm}^{2} \mathrm{did}$ not cause further extension of the optically observable oxidation. Figure 5 shows the samples after atomic oxygen exposure to a total effective fluence of $2.0 \times 10^{21}$ atoms $/ \mathrm{cm}^{2}$. An edge effect sequence of sample GS1 shown in Figure 6 demonstrates that oxidation appears to have stopped 
progressing at some point during initial exposure (the defect is a scratch in the silver). Another possible explanation is that these oxidized areas were locations of poor adhesion and were directly exposed to the atomic oxygen plasma from the beginning. This would imply that only directly exposed silver areas will oxidize, and therefore this oxidation could be preventable. Figure 7 shows the effect of atomic oxygen exposure on one of the simulated MMD impact sites in sample MD1. Oxidation occurred along some of the radial cracks that extend from the impact site. Figure 8 is a closeup of the oxidation that developed along one of these cracks and shows bright oxide "spots". These spots appear to be areas of thicker oxide growth. It was noted that the oxide around these impact sites coincides with air pockets as seen from the back of the sample. Figure 9 is a close up of the lower right radial crack in Figure 7. Figure 9a shows the oxidation from the front of the sample. Figure $9 \mathrm{~b}$ is a view of the back of the sample and shows that the oxide follows along horizontal air pockets. Figure 10, a back side view of edge oxidation on sample MD1, shows the same effect. In this area, oxidation is confided to a large air pocket (seen as a quarter circle in this micrograph). These data imply a link between oxidation and poor adhesion. Atomic oxygen exposure and the resulting oxidation caused a negligible decrease in reflectance of sample MD1. The total, diffuse and specular integrated solar values decreased from the pristine values of $0.936,0.049$ and 0.887 to $0.925,0.044$ and 0.881 , respectively, with atomic oxygen exposure as shown in Figure 11. These reflectance measurements were taken at the partially oxidized impact site shown in Figure 7.

Plasma ashers are widely used to test the atomic oxygen durability of materials, because they provide an inexpensive, high flux atomic oxygen environment for accelerated testing. There are, however, many differences between an asher and the LEO atomic oxygen environment. For example, an asher provides an isotropic arrival of oxygen atoms, where spacecraft orbiting in LEO are exposed to either fixed ram or sweeping ram atomic oxygen arrival. In addition to differences in the fluxes and arrival directions, there are differences in the initial impact reaction probabilities $\left(0.138\right.$ for space ram, and $10^{-2}-10^{-6}$ for plasma ashers, for Kapton $)^{13}$ which are dependent upon the energy and species in these environments. ${ }^{9,12}$ For durability evaluation of unprotected materials, these differences can be corrected by using effective fluence techniques. But for durability evaluation of protected materials, the differences in initial impact reaction probabilities typically result in pessimistic durability predictions for high fluences due to undercutting effects.9,14 For the microsheet glass substrate samples, no undercutting oxidation would occur because silver oxide is not volatile, and the silicone adhesive converts to silica. ${ }^{15}$ The same would be true for samples with other metal substrates such as aluminum. Yet, there could be some atomic oxygen scattering in the seams and cracks so these results could be somewhat pessimistic compared to LEO. The graphite epoxy sample could exhibit undercutting oxidation, because graphite epoxy produces a volatile oxide. Therefore, the data obtained from that sample should be considered pessimistic compared to LEO. Even though ground testing can produce pessimistic results, in all samples tested, the oxidation was confined to defects or edges. It seemed to stop propagating after initial exposure, and the total area that was oxidized is relatively small compared to the overall surface area of the mirrors. Also the reflectance was not noticeably affected at an oxidized impact site.

In all cases, the silicone adhesive seemed to be stable during atomic oxygen durability testing. There were also no observable degradation effects due to the intense $130 \mathrm{~nm}$ VUV present during atomic oxygen exposure and there was no evidence of silicone contamination 
from the adhesive exposed at the edges. It is noted that similar microsheet glass concentrator samples were exposed to thermal cycling $\left(-80^{\circ} \mathrm{C}\right.$ to $+80^{\circ} \mathrm{C}$ in air) and vacuum exposure $(92$ hours @ $10^{-6}$ torr). In these tests, an aluminum based concentrator was exposed to 5,190 thermal cycles, a magnesium based concentrator was exposed to 3,152 thermal cycles and a graphite epoxy based concentrator was exposed to 2,609 cycles. These samples were substantially larger than the atomic oxygen durability samples with microsheet glass areas $\approx 9$ $x 16 \mathrm{~cm}$ for the metal substrates and $\approx 15 \times 10 \mathrm{~cm}$ for the graphite epoxy substrate. In all cases, there were no observable changes or debonding at the glass-adhesive interface.

\section{CONCLUSIONS}

Three second surface silver microsheet glass concentrator samples were exposed to atomic oxygen in a plasma asher for durability evaluation. While oxidation from atomic oxygen exposure occurred on all samples, the region that degraded was relatively small compared to the overall surface area of the mirrors and was confined to defect sites and edges. It appears that oxidation occurred at non-adhered areas or air pockets, where the silver was directly exposed to atomic oxygen at cracks in the microsheet glass, seams or edges. The data suggest that an upper limit of degradation is reached from which point oxidation progresses no further, or progresses at an extremely slowed rate. Seams themselves do not appear to be preferential locations for oxidation. The graphite epoxy substrate sample appeared to have slightly more edge degradation than the microsheet glass substrate samples, but this may be a bonding issue. Atomic oxygen exposure and the resulting oxidation caused a negligible decrease in reflectance at a simulated impact site. Due to scattering and undercutting effects, these results should be somewhat pessimistic compared to LEO, and yet the data are very promising. Minimizing the number of air pockets along seams and edges, as well as decreasing the number of fabrication defects (such as cleaning residues) should increase the performance of these concentrators. Based on these atomic oxygen durability tests, second surface microsheet glass silver-based concentrators look very promising for advanced solar dynamic space power systems.

\section{REFERENCES}

1 Staff of Solar Dynamic Power System Branch, "Solar Dynamic Power System Development for Space Station Freedom," NASA RP 1310, July 1993.

2 Bahnman, D. W. and Jensen, P. A., "Design of a Solar Concentrator for the Solar Dynamic Ground Test Demonstration Program," Solar Engineering 1994, presented at the 1994 ASME/JSME/JSES International Solar Energy Conference, San Francisco, CA, March 27-30, 1994, pp. 193-203.

3 Jaworske, D. A., de Groh, K. K., Podojil, G. M., McCollum, T. A. and J. Anzic, "Leveling Coatings for Reducing Atomic Oxygen Defect Density in Graphite FiberEpoxy Composites," Journal of the IES, May/June 1994, pp. 26-31. 
4 de Groh, K. K., Dever, T. M. and Quinn, W. F., "The Effect of Leveling Coatings on the Atomic Oxygen Durability of Solar Concentrator Surfaces," NASA TM 102557, 1990.

$5 \quad$ Rutledge, S. K. and Olle, R. M., "Space Station Freedom Solar Array Blanket Coverlay Atomic Oxygen Durability Testing Results," 38th International SAMPE Symposium, May 10-13, 1993, pp. 679-693.

6 de Groh, K. K., Dever, J. A., McCollum, T. A., Rodriguez, E., Burke, C. and Terlep J. A., "Low Earth Orbit Durability Evaluation of Solar Concentrator Materials," Solar Engineering 1992, Vol.2, presented at the 1992 ASME/JSME/JSES International Solar Energy Conference, Maui, HI, April 5-9, 1992, pp. 775-782.

7 Rutledge, S. K. and Mihelcic, J. A., "Undercutting of Defects in Thin Film Protective Coatings on Polymer Surfaces Exposed to Atomic Oxygen," NASA TM 101986, 1989.

8 de Groh, K. K. and Banks, B. A., "Atomic-Oxygen Undercutting of Long Duration Exposure Facility Aluminized-Kapton Multilayer Insulation," Journal of Spacecraft and Rockets, Vol. 31, No. 4, July-August 1994, pp. 656-664.

9 de Groh, K. K. and Banks, B. A., "Low Earth Orbit Atomic Oxygen Simulation for Durability Evaluation of Solar Reflector Surfaces," 17th Space Simulation Conference Terrestrial Test for Space Success, NASA CP 3131, 1992, pp. 1-17.

10 Richter, S. W. and Lacy, D. E., "Overview of the NASA Lewis Advanced Microsheet Glass Concentrator Program," 1990, pp. 361-366. Solar Engineering 1990, presented at the 12th Annual ASME International Solar Energy Conference, Miami, Fl, April 1-4, 1990, pp. 775-782.

11 de Groh, K. K., Banks, B.A. and Smith D. C., "Environmental Durability Issues for Solar Dynamic Power Systems in Low Earth Orbit, " Solar Engineering 1995, Vol.2, presented at the 1995 ASME/JSME/JSES International Solar Energy Conference, Maui, HI, March 19-24, 1995, pp. 939-949, also NASA TM 106775.

12 Koontz, S. L., Albyn K. and Leger, L. J., "Atomic Oxygen Testing with Thermal Atom Systems: A Critical Evaluation," Journal of Spacecraft and Rockets, Vol. 28, No. 3, May-June, 1991, pp. 315-323.

13 Banks, B. A., Rutledge, S. K., de Groh, K. K., Stidham, C. R., Gebauer, L. and LaMoreaux, C. M., "Atomic Oxygen Durability Evaluation of Protected Polymers Using Thermal Energy Plasma Systems," NASA TM 106855, 1993.

14 Banks, B. A., Auer, B. M. Rutledge, S. K., de Groh, K. K. and Gebauer, L., "The Use of Plasma Ashers and Monte Carlo Modeling for the Projection of Atomic Oxygen Durability of Protected Polymers in Low Earth Orbit," 17th Space Simulation Conference Terrestrial Test for Space Success, NASA CP 3131, 1992, pp. 37-48. 
15 de Groh, K. K. and McCollum, T. A., "Low Earth Orbit Durability of Protected Silicone for Refractive Photovoltaic Concentrator Arrays", Journal of Spacecraft and Rockets, Vol 32, No. 1, Jan.-Feb. 1995, pp. 103-109. 

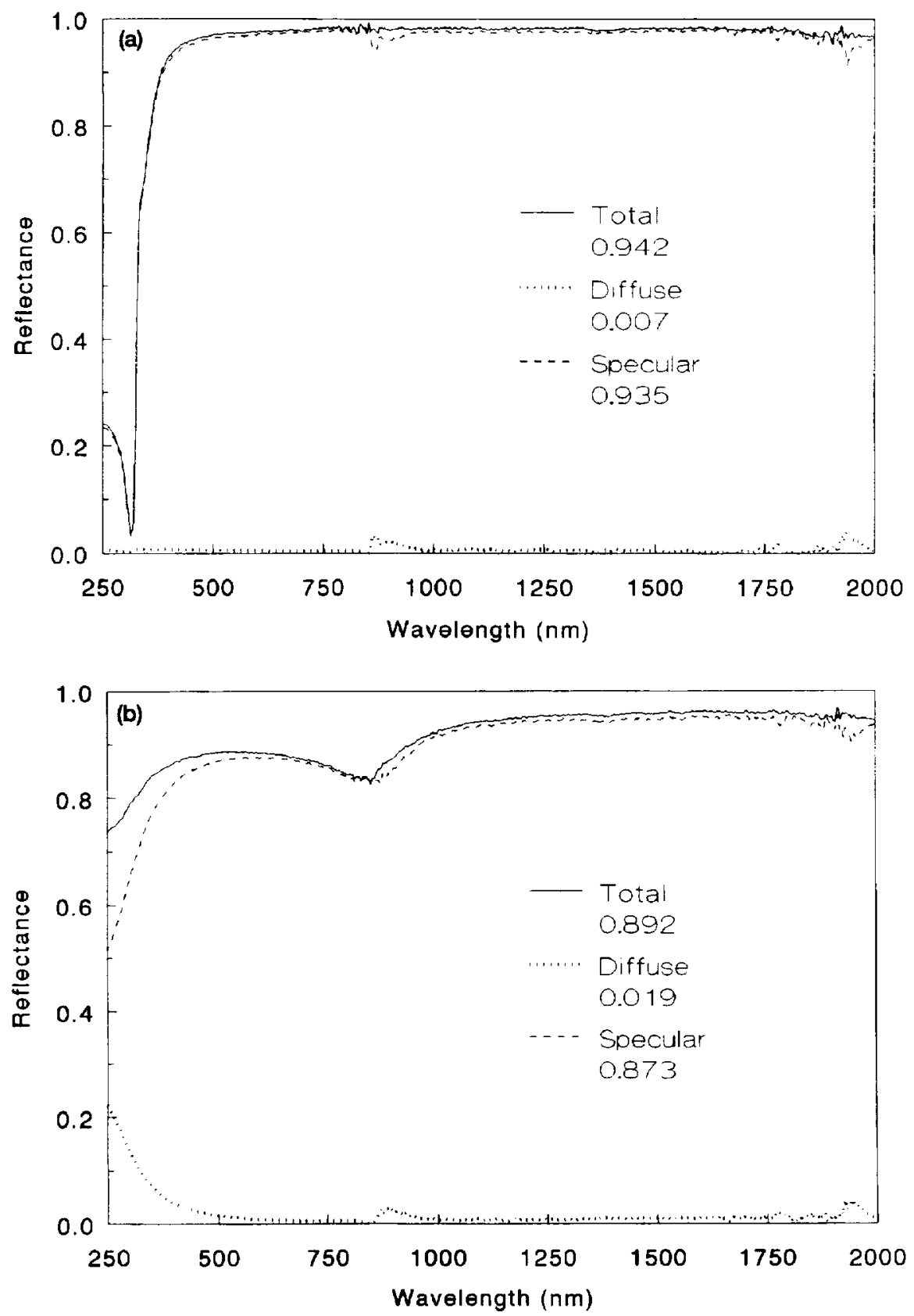

Figure 1. Spectral reflectance of first surface microsheet glass mirrors. (a) Silver mirror. (b) Aluminum mirror.

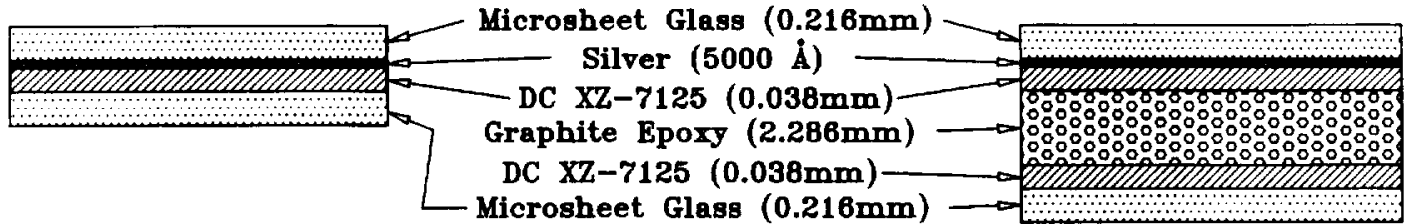

Microsheet Glass Substrate

Samples: SS1, MD1
Graphite Epoxy Substrate

Sample: GS1

Figure 2. Cross-section composition of second surface microsheet glass concentrator samples used in this study. 

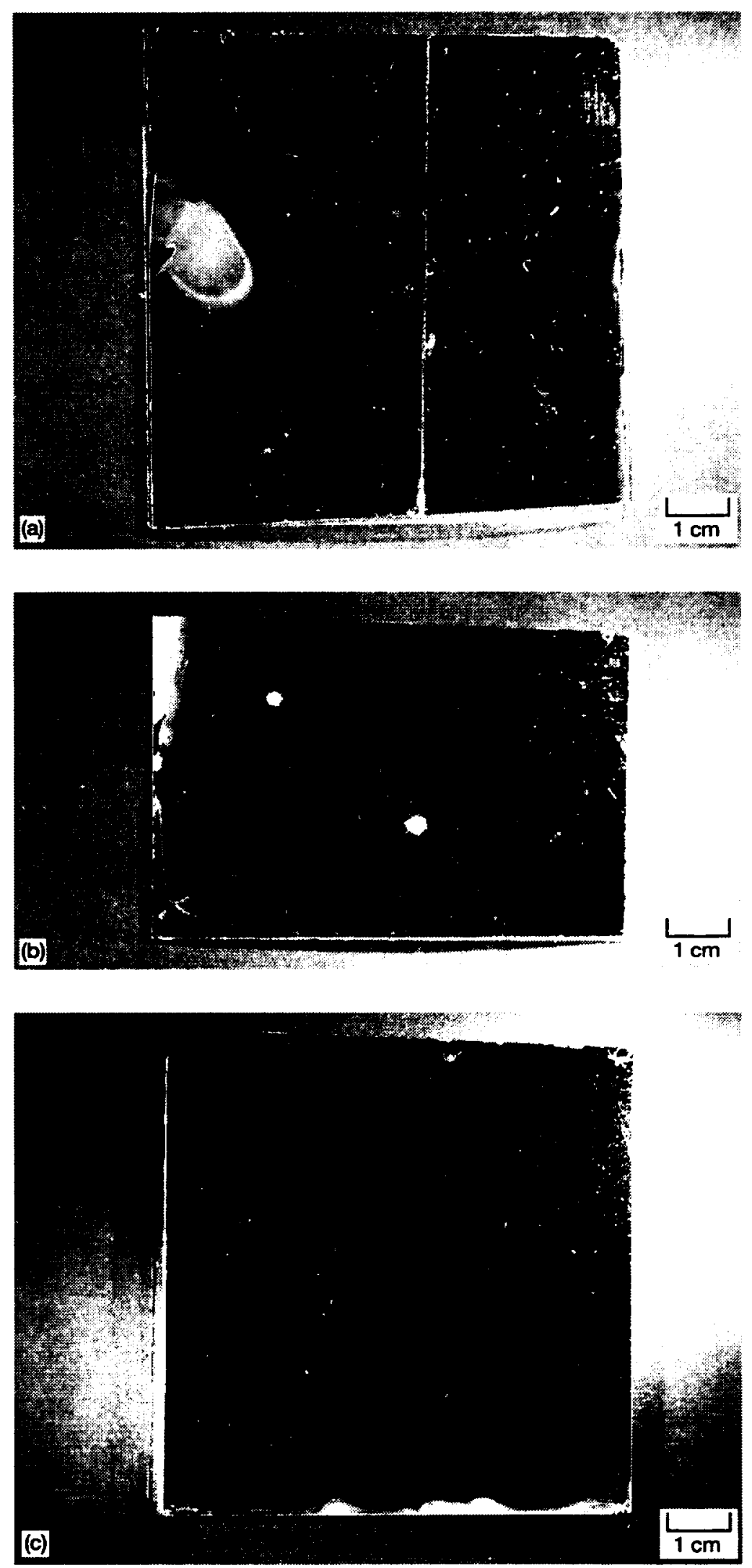

Figure 3. Pristine microsheet glass concentrator samples. (a) Sample SS1 with a seam.

(b) Sample MD1 with two impact sites. (c) Sample GS1 with a graphite epoxy substrate. 

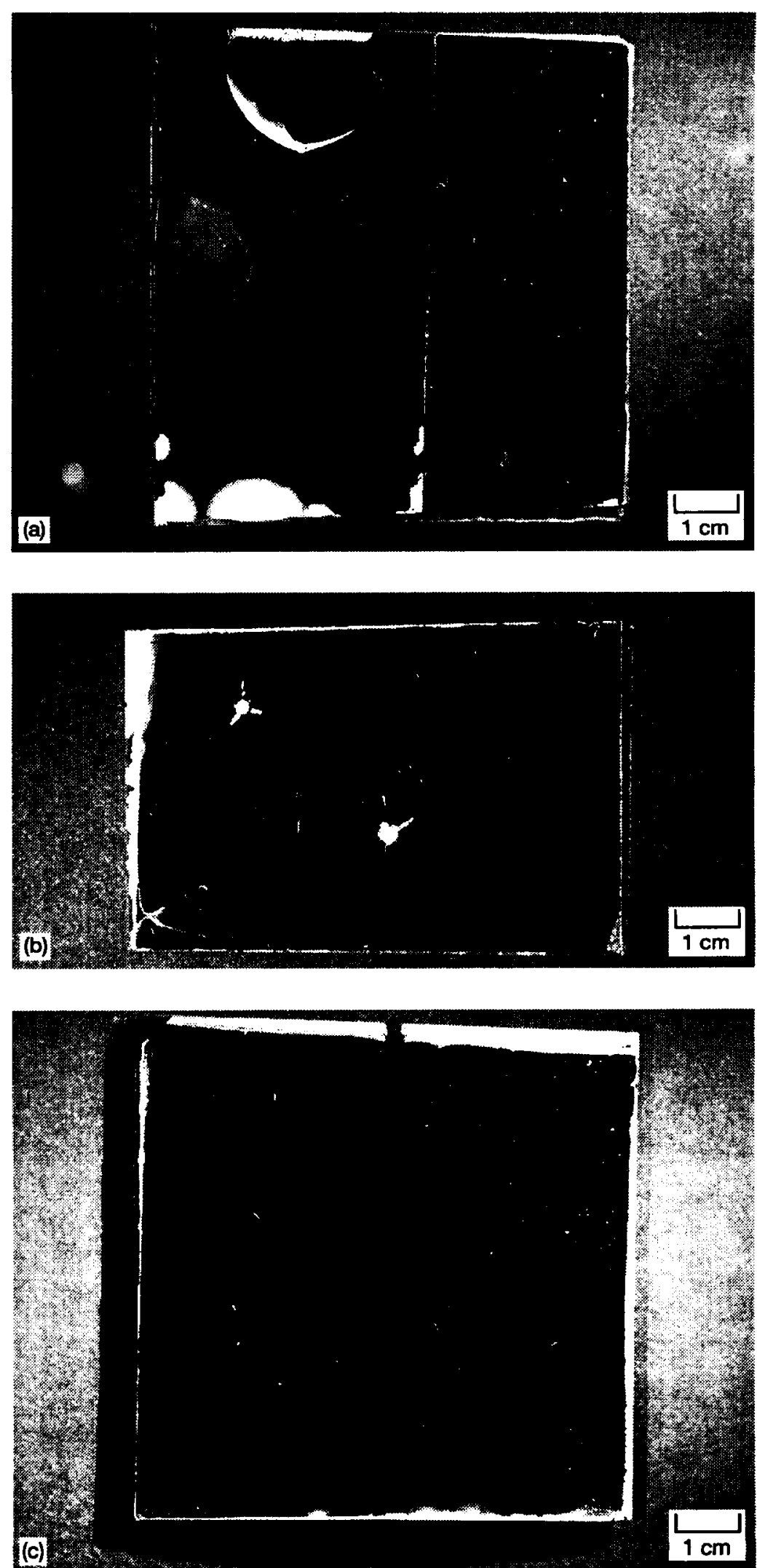

Figure 4. Microsheet glass concentrator samples after an initial atomic oxygen effective fluence of 0.7-0.9 $\times 10^{21}$ atoms $/ \mathrm{cm}^{2}$. (a) Sample SS1. (b) Sample MD1. (c) Sample GS1. 

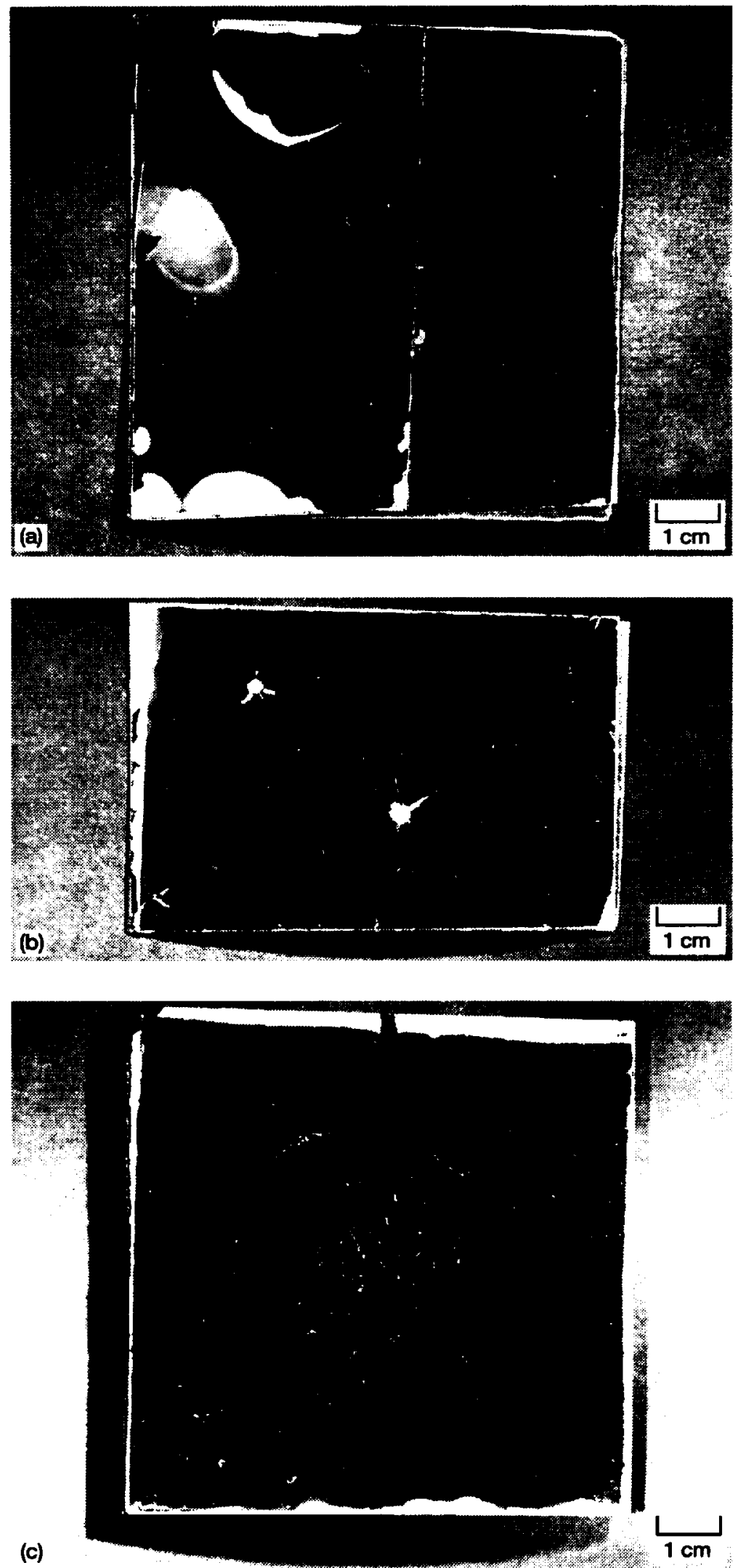

Figure 5. Microsheet glass concentrator samples after final atomic oxygen exposure to a total effective fluence of $2.0 \times 10^{21} \mathrm{atoms} / \mathrm{cm}^{2}$. (a) Sample SS1. (b) Sample MD1. (c) Sample GS1. 

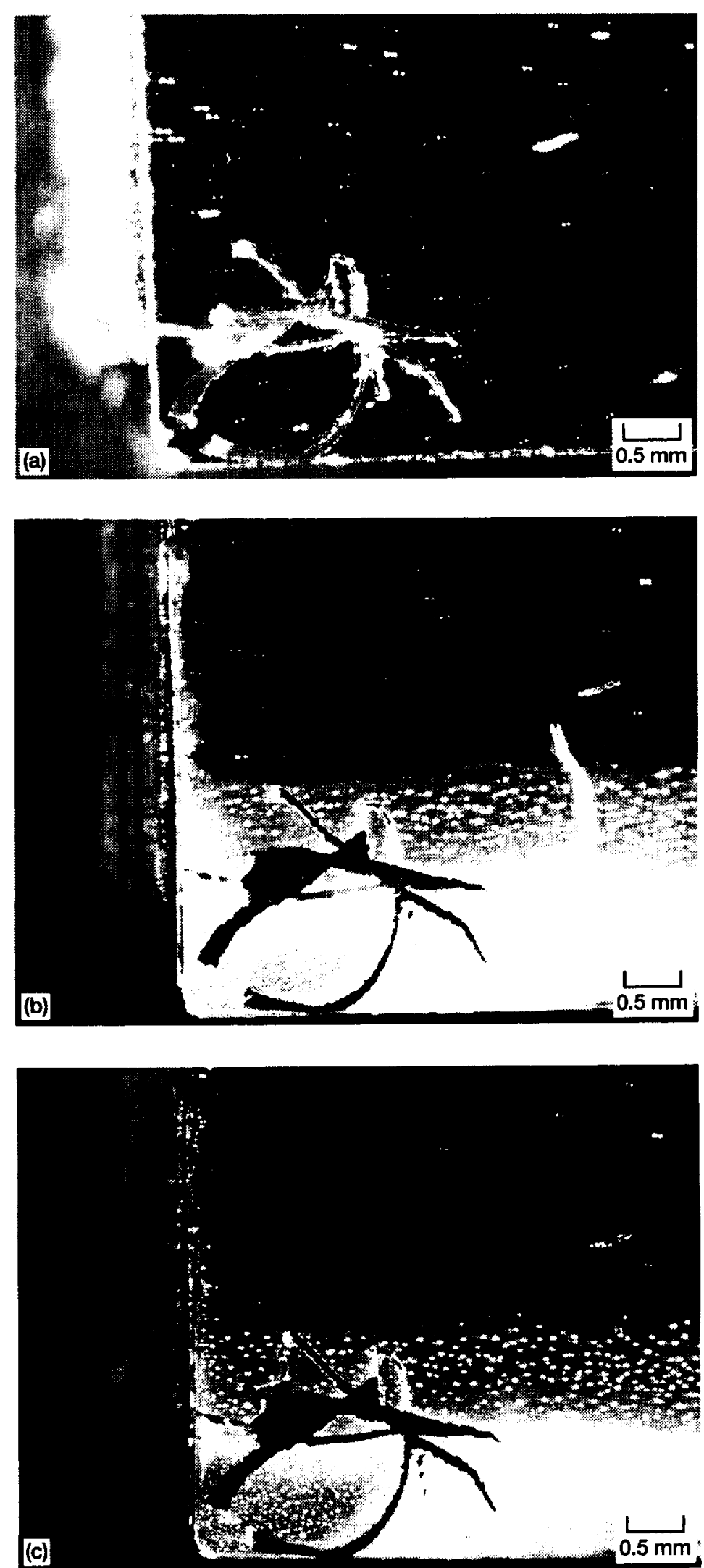

Figure 6. Comer edge of sample GS1. This sequence shows that oxidation did not progress after the initial fluence exposure. (a) Pristine. (b) Effective fluence of $1.26 \times 10^{21} \mathrm{atoms} / \mathrm{cm}^{2}$. (c) Effective fluence of $2.0 \times 10^{21} \mathrm{atoms} / \mathrm{cm}^{2}$. 

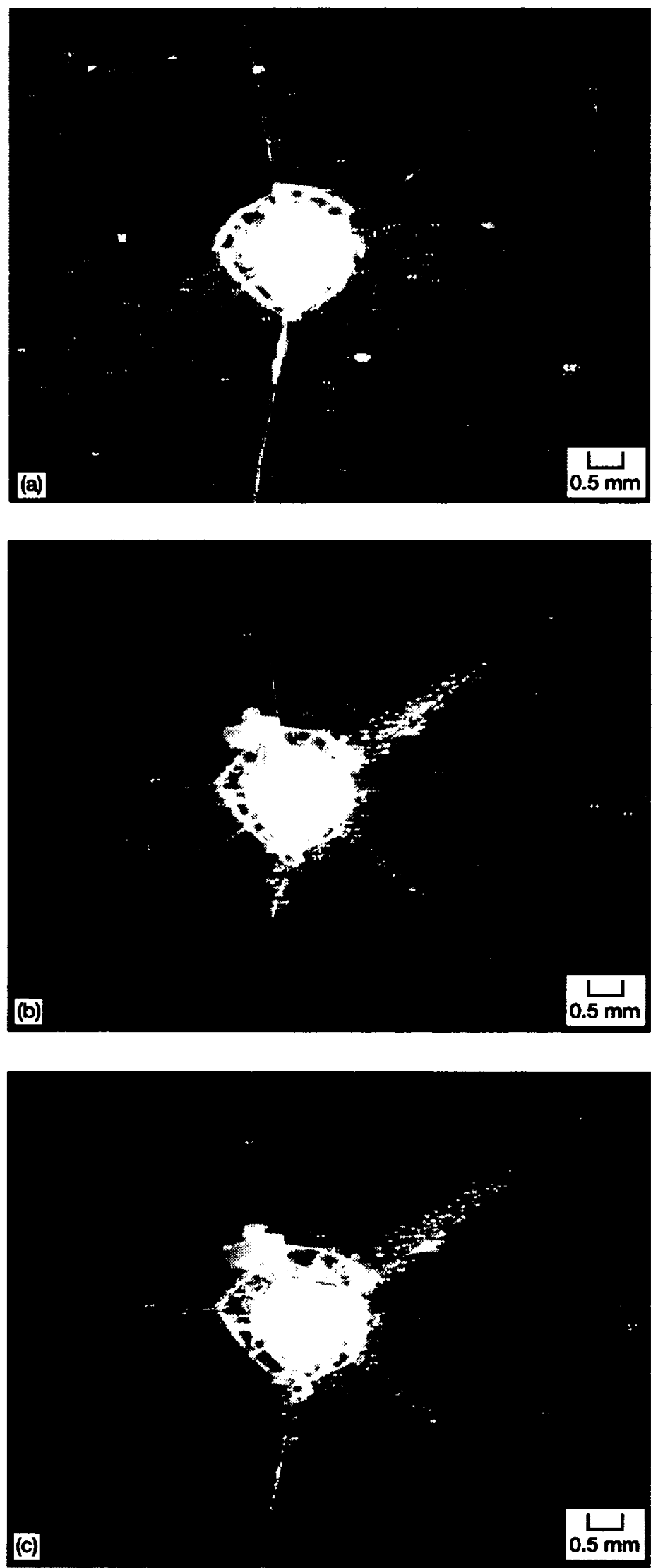

Figure 7. Impact site on sample MD1. Oxidation occurred along three of the six radial cracks. (a) Pristine. (b) Effective fluence of $1.26 \times 10^{21}$ atoms $/ \mathrm{cm}^{2}$. (c) Effective fluence of $2.0 \times 10^{21}$ atoms $/ \mathrm{cm}^{2}$. 


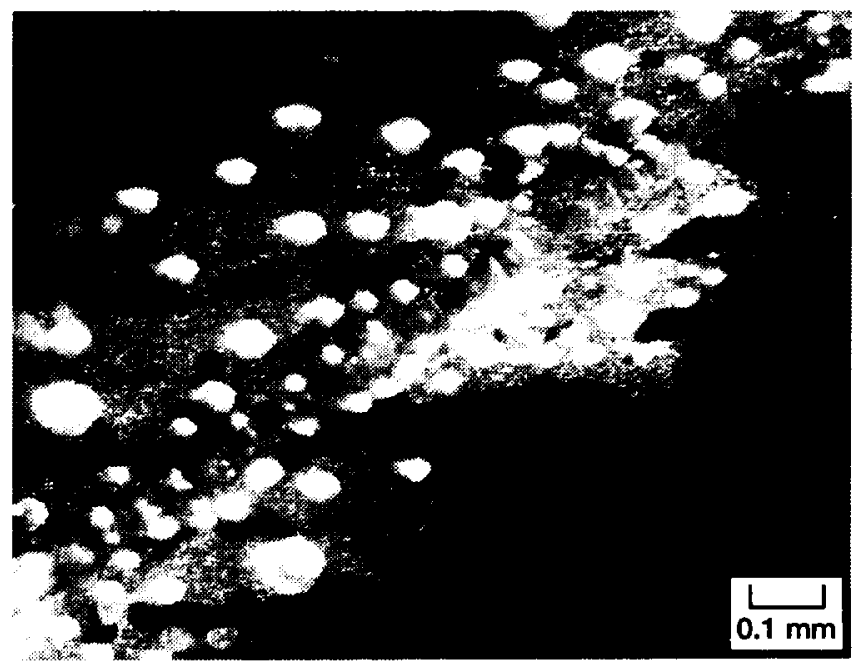

Figure 8. Sample MD1 after an effective fluence of $2.0 \times 10^{21}$ atoms $/ \mathrm{cm}^{2}$. Close-up of oxidation "spots" at a radial crack shown in Figure 7(c).
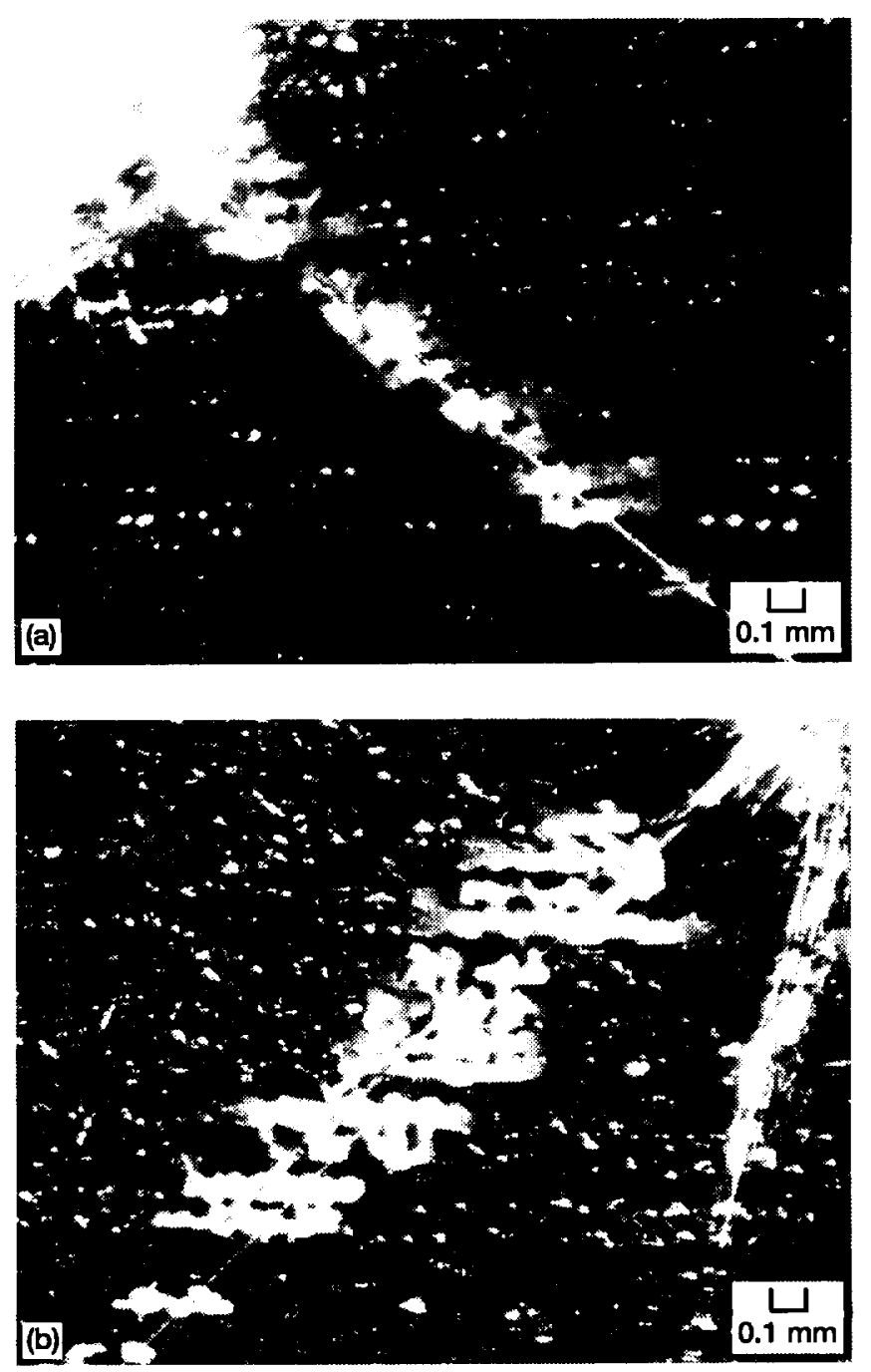

Figure 9. Lower right radial crack extending from the impact site in Figure 7. (a) Front side. (b) Back side, which shows that the oxide follows along horizontal air pockets. 


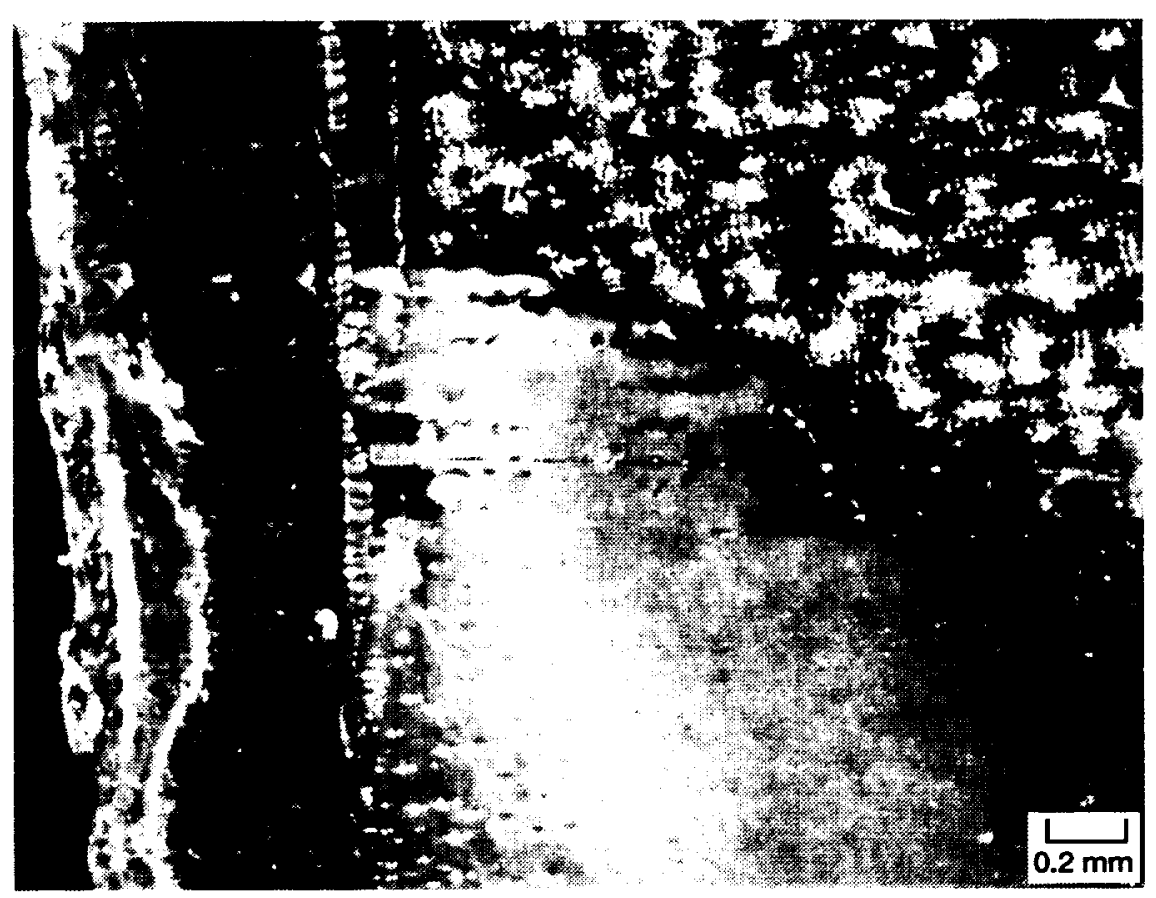

Figure 10. Back side of edge oxidation on sample MD1. Oxidation is confided to a large air pocket which is seen as a quarter circle in this micrograph.

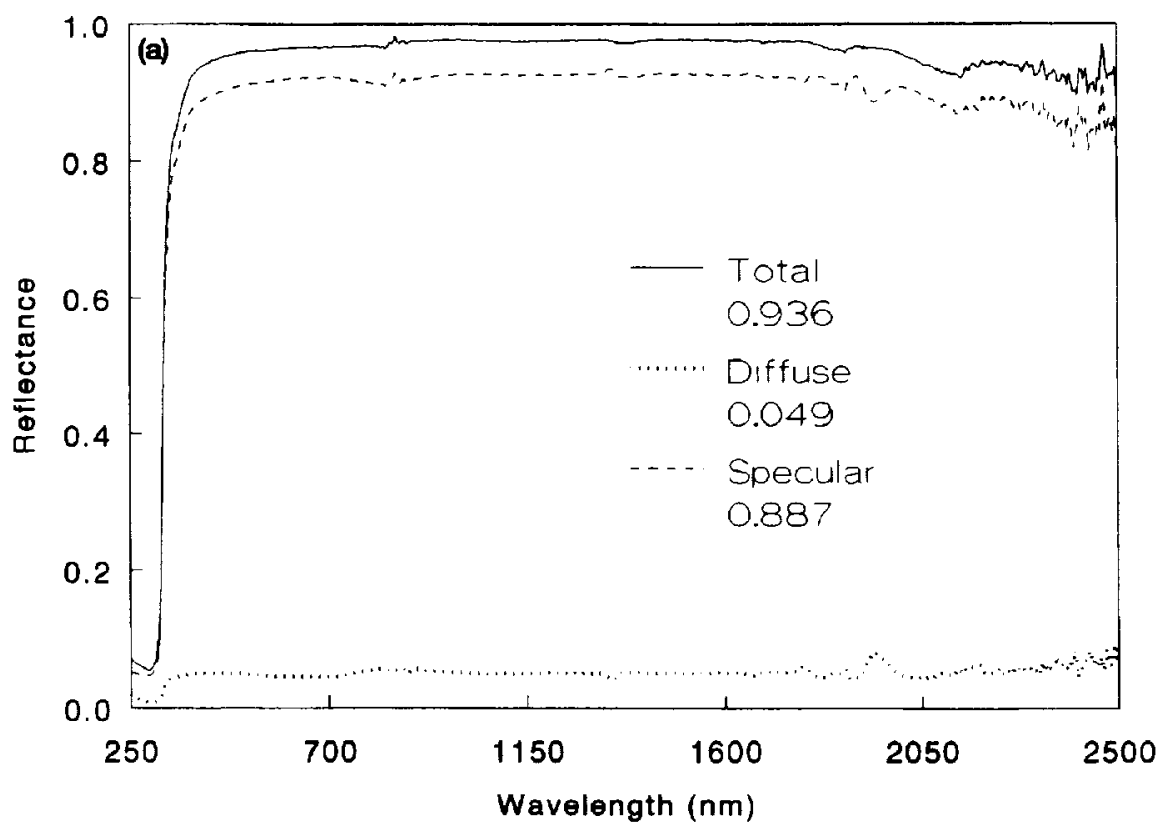

Figure 11. Spectral reflectance of sample MD1 at impact site shown in Figure 7. (a) Pristine. (b) Effective fluence of $1.26 \times 10^{21}$ atoms $/ \mathrm{cm}^{2}$. (c) Effective fluence of $2.0 \times 10^{21}$ atoms $/ \mathrm{cm}^{2}$. 
Public reponting burden for this collection of Information is extimated 10 average 1 hour per reeponee, including the time tor reviewing instructions, searching exiating data sources, gathering and maintaining the data needed, and completing and revlewing the collection of information. Send cormments regarding this burden eatimats of any other aspect of this collection of intormation, including suggestions for reducing this burden, to Washington Headquarters Senvices, Directorate for Information Operations and Peporta, 1215 Jelien

1. AGENCY USE ONLY (Leave blank) 2. REPORT DATE
April 1996 3. REPORT TYPE AND DATES COVERED

4. TIRE AND SUBTILE

Atomic Oxygen Durability of Second Surface Silver Microsheet Glass Concentrators

6. AUTHOR(S)

WU-233-1A-1E

Kim K. de Groh, Donald A. Jaworske, Daniela C. Smith, and Thaddeus S. Mroz

7. PERFORIING ORGANIZATION MAME(S) AND ADDRESS(ES)

8. PERForimg organization REPORT NUMBEA

National Aeronautics and Space Administration

Lewis Research Center

Cleveland, Ohio 44135-3191

E-10226

9. SPONSORINGMONTOOANG AGENCY MAME(SY AND ADDRESS(ES)

10. SPONSORINGMONTOAING AGENCY REPORT NUMBER

National Aeronautics and Space Administration

Washington, D.C. 20546-0001

NASA TM-107210

\section{SUPPLENENTARY NOTES}

Prepared for the Third Intemational Conference on Protection of Materials and Structures from the Low Earth Orbit Space Environment cosponsored by the Canadian Space Agency and the Instinure for Space and Terrestrial Studies, Toronto, Canada, April 25-26, 1996. Kim K. de Groh and Donald A. Jaworske, NASA Lewis Research Center, Daniela C. Smith, Cleveland State University, Cleveland, Ohio 44115; Thaddeus S. Mroz, Distinguished Research Associare, NASA Lewis Research Center. Responsible person, Kim K. de Groh, organization code 5480, (210) 433-2297.

12a. DISTPIBUTIONAVALABILTYY STATENENT

Unclassified - Unlimited

Subject Category 20

This publication is available from the NASA Ceater for AeroSpace Information, (301) 621-0390.

13. ABSTRACT (Maximum 200 words)

Second surface silver microsheet glass concentrators are being developed for potential use in future solar dynamic space power systems. Traditional concentrators are aluminum honeycomb sandwich composites with either aluminum or graphite epoxy face sheets, where a reflective aluminum layer is deposited onto an organic leveling layer on the face sheet. To protect the underlying layers, a SiO 2 layer is applied on top of the aluminum reflective layer. These concentrators may be vulnerable to atomic oxygen degradation due to possible atomic oxygen attack of the organic layers at defect sites in the protective and reflective coatings. A second surface microsheet glass concentrator would be inherently more atomic oxygen durable than these first surface concentrators. In addition, a second surface microsheet glass concentrator design provides a smooth optical surface and allows for silver to be used as a reflective layer, which would improve the reflectivity of the concentrator and the performance of the system. A potential threat to the performance of second surface microsheet glass concentrators is atomic oxygen attack of the underlying silver at seams and edges or at micrometeoroid and debris (MMD) impacts sites. Second surface silver microsheet glass concentrator samples were fabricated and tested for atomic oxygen durability. The samples were iteratively exposed to an atomic oxygen environment in a plasma asher. Samples were evaluated for potential degradation at fabrication seams, simulated MMD impact sites, and edges. Optical microscopy was used to evaluate atomic oxygen degradation. Reflectance was obtained for an impacted sample prior to and after atomic oxygen exposure. After an initial atomic oxygen exposure to an effective fluence of $\approx 1 \times 10^{21}$ atoms $/ \mathrm{cm}^{2}$, oxidation of the silver at defect sites and edges was observed. Exposure to an additional $\approx 1 \times 10^{21}$ atoms $/ \mathrm{cm}^{2}$ caused no observed increase in oxidation. Oxidation at an impact site caused negligible changes in reflectance. In all cases oxidation was found to be confined to the vicinity of the seams, impact sites, edges or defect sites. Asher to in-space atomic oxygen correlation issues will be addressed.

\begin{tabular}{|c|c|c|}
\hline \multicolumn{3}{|l|}{ 14. SUBJECT TERMS } \\
\hline \multicolumn{3}{|c|}{$\begin{array}{l}\text { Atomic oxygen; Solar concentrator, Microsheet glass; Durability; Plasma asher; } \\
\text { Reflectivity }\end{array}$} \\
\hline $\begin{array}{l}\text { 17. SECURTY CLASSIFICATION } \\
\text { OF REPORT } \\
\text { Unclassified }\end{array}$ & $\begin{array}{l}\text { 18. SECURTY CLASSIFICATION } \\
\text { OF THIS PAGE } \\
\text { Unclassified }\end{array}$ & $\begin{array}{l}\text { 19. SECUPITY CLASSIFICATION } \\
\text { OF ABSTRACT } \\
\text { Unclassified }\end{array}$ \\
\hline
\end{tabular}

16. PRICE CODE A03

20. LIMTAATION OF ABSTRACT 

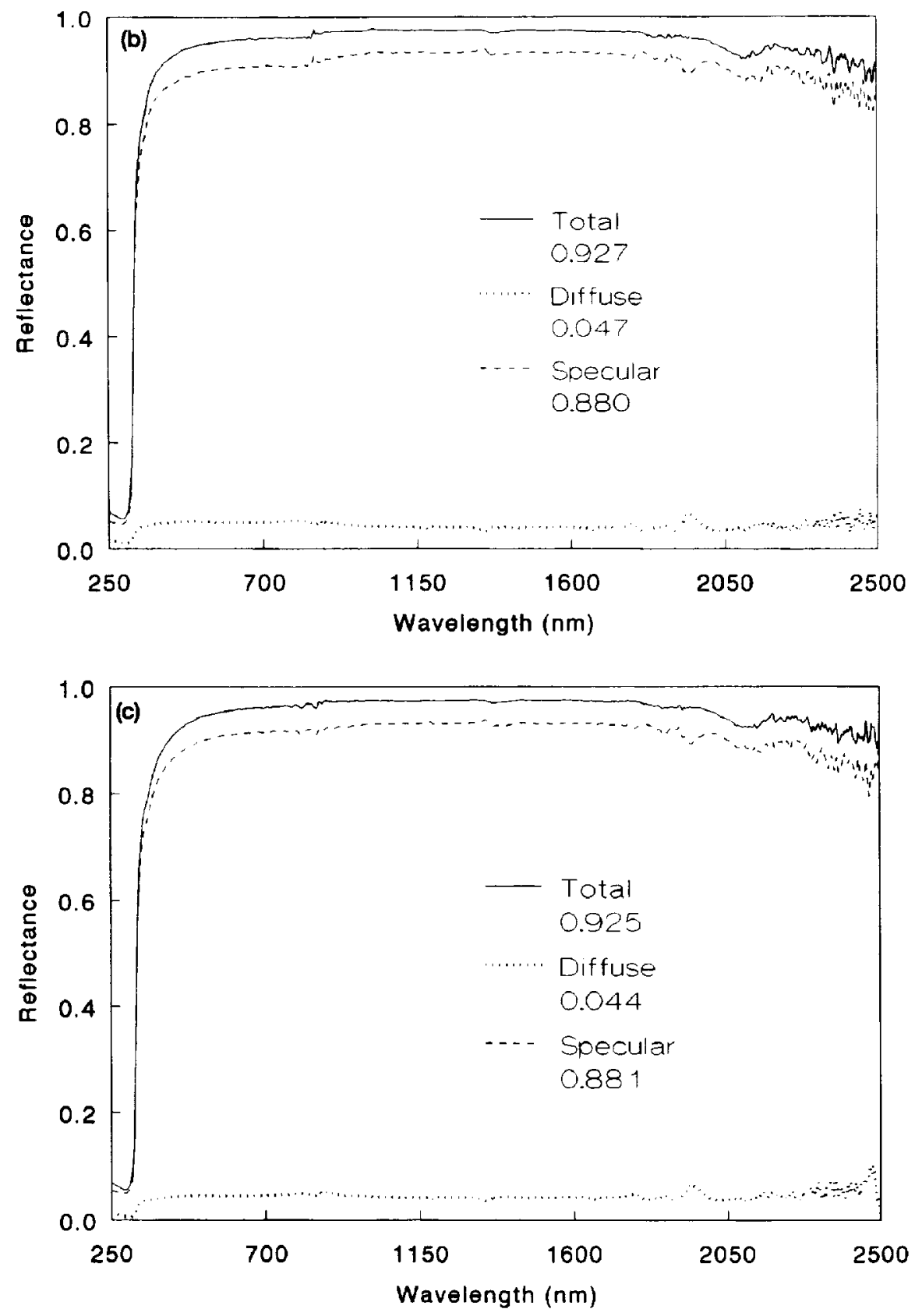

Figure 11. Concluded. (b) Effective fluence of $1.26 \times 10^{21} \mathrm{atoms} / \mathrm{cm}^{2}$. (c) Effective fluence of $2.0 \times 10^{21}$ atoms $/ \mathrm{cm}^{2}$. 

, 


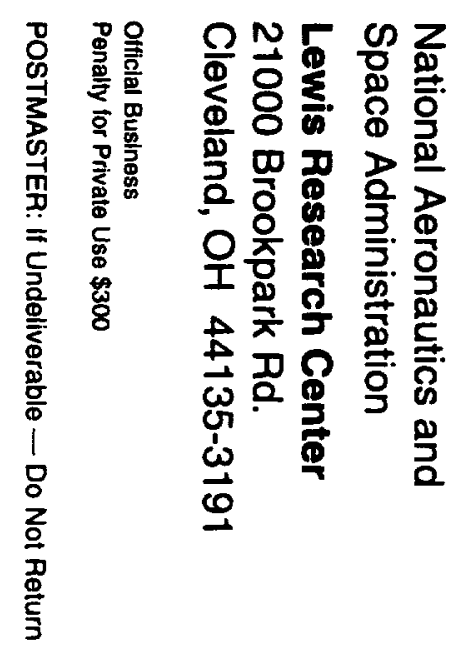

